Pesq. Vet. Bras. 36(3):167-173, março 2016 DOI: $10.1590 /$ S0100-736X2016000300004

\title{
Determinação de valores de referência séricos para os eletrólitos magnésio, cloretos, cálcio e fósforo em ovinos das raças Dorper e Santa Inês ${ }^{1}$
}

\author{
Bianca C. Souza ${ }^{2}$, Ludmilla S. Sena², Dan Loureiro², José T. Raynal ${ }^{2}$, Thiago J. Sousa ${ }^{3}$, \\ Bruno L. Bastos ${ }^{4}$, Roberto Meyer $^{2}$ e Ricardo W. Portela ${ }^{2 *}$
}

\begin{abstract}
Souza B.C., Sena L.S., Loureiro D., Raynal J.T., Souza T.J., Bastos B.L., Meyer R. \& Portela R.W. 2016. [Determination of magnesium, chloride, calcium and phosphorus serum reference values for Dorper and Santa Inês sheep breeds.] Determinação de valores de referência séricos para os eletrólitos magnésio, cloretos, cálcio e fósforo em ovinos das raças Dorper e Santa Inês. Pesquisa Veterinária Brasileira 36(3):167-173. Laboratório de Imunologia e Biologia Molecular, Instituto de Saúde Coletiva, Universidade Federal da Bahia, Av. Reitor Miguel Calmon s/n, Vale do Canela, Salvador, BA 40110-100, Brazil. E-mail: rwportela@gmail.com

The sheep industry in Brazil is an important economic activity, and with the increasing global demand for sheep meat there is a great interest in the monitoring of the herd health, and serum reference ranges are basic tools for veterinary clinical pathology assays. Mineral elements correspond to $2-5.5 \%$ of the body of vertebrates, holding different functions in their physiology. The objective of this study was to obtain reference intervals of the electrolytes magnesium, phosphorus, chloride and calcium for the Dorper and Saint Ines sheep breeds. Sera samples were collected from 487 clinically healthy sheep, 146 from Dorper and 341 from Santa Ines breed. Electrolytes were measured using commercial kits. Data were analyzed taking the race, sex and age variables in account, and reference ranges were established. The results revealed significant statistical differences in reference ranges obtained for the electrolytes calcium and magnesium concerning the variable race, and for the electrolyte phosphorus in the variable age and, when compared with reference values already published, proved the existence of significant differences.
\end{abstract}

INDEX TERMS: Serum reference values, sheep, magnesium, chloride, calcium, phosphorus, electrolytes, clinical biochemistry.

RESUMO.- A ovinocultura no Brasil é uma atividade em grande expansão e, com o aumento da demanda mundial por carne ovina, aumentou-se o interesse no monitoramento da sanidade do rebanho, utilizando diversas ferramentas como auxiliares no diagnóstico clínico, tais como os intervalos de

\footnotetext{
${ }^{1}$ Recebido em 23 de setembro de 2015.

Aceito para publicação em 6 de janeiro de 2016.

${ }^{2}$ Laboratório de Imunologia e Biologia Molecular, Instituto de Saúde Coletiva (ICS), Universidade Federal da Bahia (UFBA), Av. Reitor Miguel Calmon s/n, Vale do Canela, Salvador, BA 40110-100, Brasil. *Autor para correspondência: rwportela@gmail.com

${ }^{3}$ Laboratório de Genética Celular e Molecular, Instituto de Ciências Biológicas (ICB), Universidade Federal de Minas Gerais (UFMG), Av. Presidente Antônio Carlos 6627, Belo Horizonte, MG 31270-901, Brasil.

${ }^{4}$ Instituto Multidisciplinar em Saúde, UFBA, Rua Rio de Contas 58, Vitória da Conquista, BA 45.029-094, Brasil.
}

referência séricos. Os elementos minerais constituem 2 a $5,5 \%$ do corpo dos vertebrados, exercendo diversas funções no organismo. 0 objetivo deste trabalho foi obter intervalos de referência para os eletrólitos magnésio, fósforo, cloreto e cálcio para ovinos das raças Dorper e Santa Inês. Foram coletados soros de 487 animais clinicamente sadios, sendo 146 da raça Dorper e 341 da raça Santa Inês. Os eletrólitos foram mensurados utilizando-se kits comerciais. Os dados foram analisados quanto à raça, sexo e idade, e os intervalos de referência determinados. Os resultados revelaram diferenças significativas nos intervalos de referência obtidos para os eletrólitos cálcio e magnésio na variável raça, e para o eletrólito fósforo na variável faixa etária e, quando confrontados com valores de referência já publicados, comprovou-se a existência de diferença estatística significativa entre os mesmos em todos os analitos estudados. 
TERMOS DE INDEXAÇÃO: Valores de referência sérica, ovinos, magnésio, cloretos, cálcio, fósforo, eletrólitos, bioquímica clínica.

\section{INTRODUÇÃO}

A ovinocultura no Brasil é uma alternativa de exploração pecuária que vem alcançando grande desenvolvimento, principalmente devido ao aumento da demanda de produção de carne. A criação de ovinos de corte da raça Santa Inês vem crescendo entre os produtores pela rusticidade da raça e capacidade de adaptação às diversas condições climáticas e econômicas das regiões brasileiras, destacando-se a Nordeste (Cruz 2009). A raça Dorper apresenta alta taxa de desenvolvimento de carcaça com boa conformação, sendo muito utilizada em cruzamentos com ovelhas de raças nativas do Nordeste, tais como a Santa Inês, em virtude do seu porte e da velocidade de crescimento (Carneiro et al. 2007). Também já foi descrito que características genéticas da raça Dorper conferem maior resistência a parasitos gastrointestinais (Benavides et al. 2015), o que torna essa raça de alto interesse para criação em regiões brasileiras caracterizadas por alta infestação com esses parasitos (Wilmsen et al. 2014).

Com o objetivo de aumentar a produção de carne ovina, aumentou-se o interesse no monitoramento da sanidade do rebanho, utilizando diversas ferramentas como auxiliares no diagnóstico clínico, tais como os intervalos de referência para metabólitos sanguíneos (componentes hemato-bioquímicos) (Peixoto \& Osório 2007). De acordo com a definição da International Federation of Clinical Chemistry (IFCC), valores de referência são determinados em uma população bem definida de indivíduos saudáveis selecionados de acordo com critérios preestabelecidos (Geffré et al. 2009). Estes valores podem variar significativamente de uma população estudada para outra, já que fatores como gestação, idade, sexo e raça, dentre outros, tem influência direta na concentração de alguns analitos pesquisados (CLSI 2008).

Os elementos minerais constituem 2 a 5,5\% do corpo dos animais vertebrados. Devido à diversidade de funções que exercem no organismo, são importantes em diversos processos de bioquímica fisiológica (Geraseev et al. 2001). Os cloretos são os ânions mais abundantes no compartimento extracelular, e a concentração no plasma e a eliminação destes íons são usualmente concomitantes com as do sódio. Os íons magnésio são importantes para a manutenção da integridade do DNA e também são cofatores essenciais para inúmeras enzimas envolvidas nos processos de reparo ao DNA (Kaneko 2008). 0 cálcio tem um papel importante na liberação do sítio ativo das pontes cruzadas actina-miosina durante a contração muscular, e são transportados de volta ao líquido endoplasmático após a contração muscular (Bucci et al. 2006). A energia proveniente da alimentação é armazenada em forma de ATP (adenosina trifosfato), composta por três íons fósforo, e os ATPs representam o reservatório de energia potencial, que poderá ser usado nos diversos processos biológicos do organismo que necessitem de energia, como a contração muscular (Rossi \& Tirapegui 1999).

O objetivo deste trabalho foi obter valores de referência para os eletrólitos magnésio, fósforo, cloretos e cálcio em ovinos das raças Dorper e Santa Inês. Pode-se achar na literatura científica trabalhos sobre intervalos de referência para proteínas séricas de ovinos (Miglio et al. 2015), mas ainda não foram publicados trabalhos detalhados sobre os intervalos de referência dos referidos eletrólitos nas raças supracitadas e em condições de criação semi-intensiva.

\section{MATERIAL E MÉTODOS}

Foram utilizadas neste trabalho 784 amostras de soros de ovinos clinicamente saudáveis das raças Dorper e Santa Inês oriundos de diversas regiões do Estado da Bahia. Todos esses animais tinham registro na Associação Brasileira de Criadores de Ovinos (ARCO) ou na Associação de Criadores de Caprinos e Ovinos do Estado da Bahia (ACCOBA), o que os certifica como sendo animais pertencentes a cada raça. Além disso, todos passaram por rigorosa avaliação clínica veterinária quanto à coloração de mucosas, estado de hidratação, temperatura corporal, ocorrência de linfoadenomegalia ou esplenomegalia, e realização de metodologia FAMACHA para detecção de possíveis infectados com helmintos. Os animais que apresentavam quaisquer alterações nesses parâmetros não foram incluídos no estudo. Fêmeas submetidas a inseminação artificial ou monta natural, ou com sintomas de gestação, também foram excluídas. Foi verificado também que todos os animais incluídos tivessem tratamento antiparasitário rigoroso. Desses animais, através de informações das Associações de Criadores e com base no número de registro de cada um, foi possível identificar a raça de 487, sendo que 146 eram da raça Dorper e 341 eram da raça Santa Inês. Também foi possível identificar a faixa etária de 250 animais, e o sexo de 486 animais. Uma exposição mais informativa do número de animais estudados, com o número de animais com identificação de raça, sexo e idade pode ser visto no Quadro 1.

As coletas de sangue foram realizadas por venopunção jugular, utilizando-se tubos de coleta à vácuo sem anticoagulante. Para a obtenção de soro, os tubos foram centrifugados a 4.000 RPM durante dez minutos. As amostras de soros foram aliquotadas em microtubos e mantidas em freezer a -20ㅇ C até o seu uso.

Para a mensuração dos eletrólitos, foram utilizados kits comerciais (Labtest Diagnóstica S. A., Lagoa Santa, Minas Gerais), aliados à utilização de espectrofotômetro (Cary 50Bio, VARIAN, Palo Alto, California, EUA). As instruções de uso fornecidas pelo fabricante foram seguidas. Antes da realização dos procedimentos, todo o material utilizado para a mensuração passou uma série de três lavagens com água deionizada e bidestilada e álcool 70\%, com o objetivo de retirar as impurezas e os resíduos de eletrólitos. Cada amostra foi medida em duplicata, sendo que os resultados

Quadro 1. Número de animais incluídos no estudo, e divisão por raça, sexo e idade

\begin{tabular}{lc}
\hline Variáveis & Número de animais \\
\hline Raça & 487 \\
Dorper & 146 \\
Santa Inês & 341 \\
Sexo & 486 \\
Macho & 150 \\
Fêmea & 336 \\
Idade & 250 \\
0 - 6 meses & 49 \\
6 - 12 meses & 104 \\
12 - 24 meses & 80 \\
24 - 36 meses & 17 \\
Animais com especificação de variáveis & 487 \\
Animais sem especificação de variáveis & 297 \\
Total & 784
\end{tabular}


obtidos representam a média dessas duplicatas. Um resumo dos kits comerciais utilizados e das metodologias empregadas está descrito no Quadro 2.

Os íons magnésio foram mensurados por reação de ponto final: em meio alcalino, os íons reagem com o magon sulfonado (cor azul), formando um complexo de cor rósea (complexo magnésio-magon) que é proporcional à quantidade de íons magnésio na amostra, medido colorimetricamente a $505 \mathrm{~nm}$ (Bohuon 1962). Os íons fósforo foram também mensurados por reação de ponto final: eles reagem com o molibdênio em meio ácido, formando um complexo amarelo, que por ação de um tampão alcalino é reduzido a azul-molibdênio, o qual foi medido colorimetricamente a 650nm (Baginsk 1969). Com relação aos íons cloretos, foi realizada reação de ponto final onde os mesmos reagem com o tiocianato de mercúrio formando o cloreto mercúrico e íons tiocianato; estes reagem com os íons férrico, formando o tiocianato férrico de cor amarela, o qual foi medido colorimetricamente a 450nm (Burtis \& Ashwood 1994). Para os íons cálcio, foi realizada reação onde os mesmos reagem com a púrpura de cresolftaleína em meio alcalino, formando um complexo de cor violeta de intensidade proporcional à concentração de cálcio na amostra, medido colorimetricamente a 595nm (Cooper 1983).

Todos os dados obtidos foram inseridos no software EXCEL

\section{Quadro 2. Kits comerciais e metodologias empregadas na mensuração dos eletrólitos cloretos, magnésio, cálcio e fósforo}

\begin{tabular}{|c|c|c|c|c|}
\hline Eletrólito & $\begin{array}{c}\text { Nome do kit } \\
\text { utilizado }\end{array}$ & Marca & Metodologia & Procedimento \\
\hline Cloretos & Cloretos & Labtest & $\begin{array}{l}\text { Tiocianato } \\
\text { mercúrio }\end{array}$ & Ponto final \\
\hline Magnésio & Magnésio & Labtest & $\begin{array}{c}\text { Magon } \\
\text { sulfonado }\end{array}$ & Ponto final \\
\hline Cálcio & Cálcio Liquiform & Labtest & Cresolftaleína & Ponto final \\
\hline Fósforo & Fósforo & Labtest & Molibdato & Ponto final \\
\hline
\end{tabular}

(Microsoft Office 2007, Microsoft Corporation, Redmond, Washington, USA) para a realização das análises iniciais. Primeiramente, foram calculados o desvio padrão e as médias entre as duplicatas das amostras. Logo após, as médias dos valores das densidades ópticas (D.0.) foram transformadas em unidades de concentração de acordo com os cálculos fornecidos pelo fabricante dos kits. Os valores aberrantes ou atípicos (outliers) foram detectados e descartados seguindo o procedimento de Tukey, onde uma amostra é definida como outlier quando seu valor for menor que o primeiro quartil menos 1,5 vezes o intervalo interquartil, ou maior que o terceiro quartil mais 1,5 vezes o intervalo interquartil (Friedberg et al, 2007). Os dados foram transferidos para o software estatístico SPSS versão 18 (Statistical Package for the Social Sciences, SPSS Inc., Chicago, Illinois, USA), onde foram realizadas as análises estatísticas. Avaliando-se a distribuição dos dados, foi concluído que os mesmos eram paramétricos. Foram feitas análises de média, mediana, range, valor mínimo e valor máximo, 95\% de intervalo de confiança da mediana e desvio padrão. Semelhante à análise proposta por Borjesson et al. (2000), foi realizado um teste para amostras independentes (oneway ANOVA) para comparar medianas e avaliar a significância estatística atribuída para as variáveis raça, sexo e idade para todos os analitos. Os valores cujo $p<0,05$ foram considerados estatisticamente significantes. Para variáveis (raça, sexo e idade) consideradas significativas, foram calculados intervalos de referência separadamente.

\section{RESULTADOS}

Após a retirada dos outliers e contabilização das perdas, o número de amostras foi reduzido, ficando da seguinte forma: 678 para os íons magnésio e fósforo, 666 para os ânions cloreto e 570 para os íons cálcio.

A Figura 1 mostra os resultados para a mensuração de magnésio apresentados em formato de gráfico boxplot, de acordo com a raça estudada (1A), idade (1B) e sexo (1C).
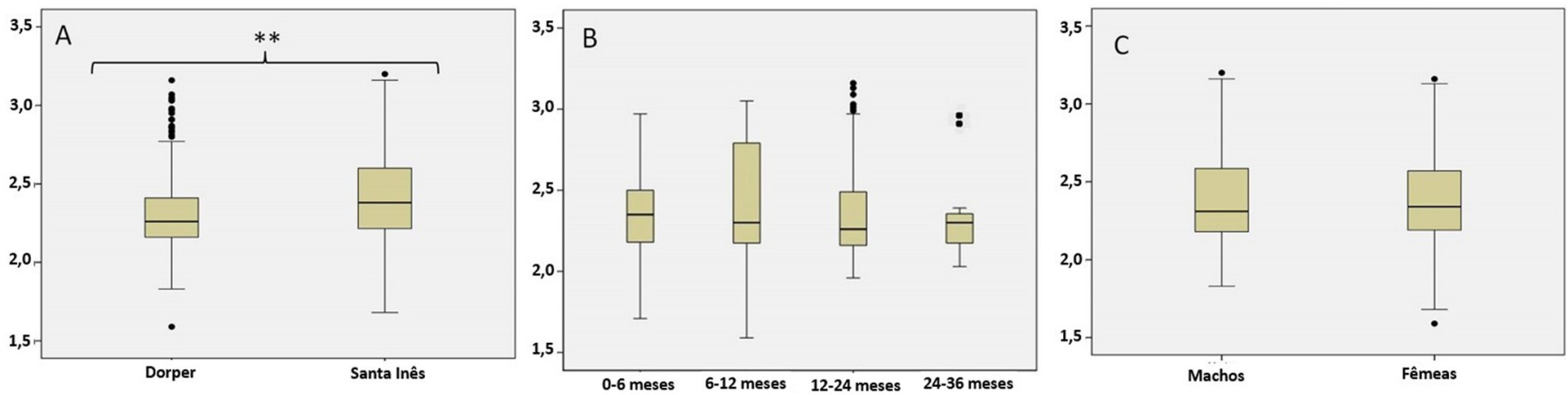

Fig.1. Distribuição dos dados de mensuração do íon magnésio sérico para as variáveis (A) raça, (B) idade e (C) sexo. 0 símbolo “**” representa diferença estatística no teste one-way ANOVA no grau de significância de $p=0,001$.
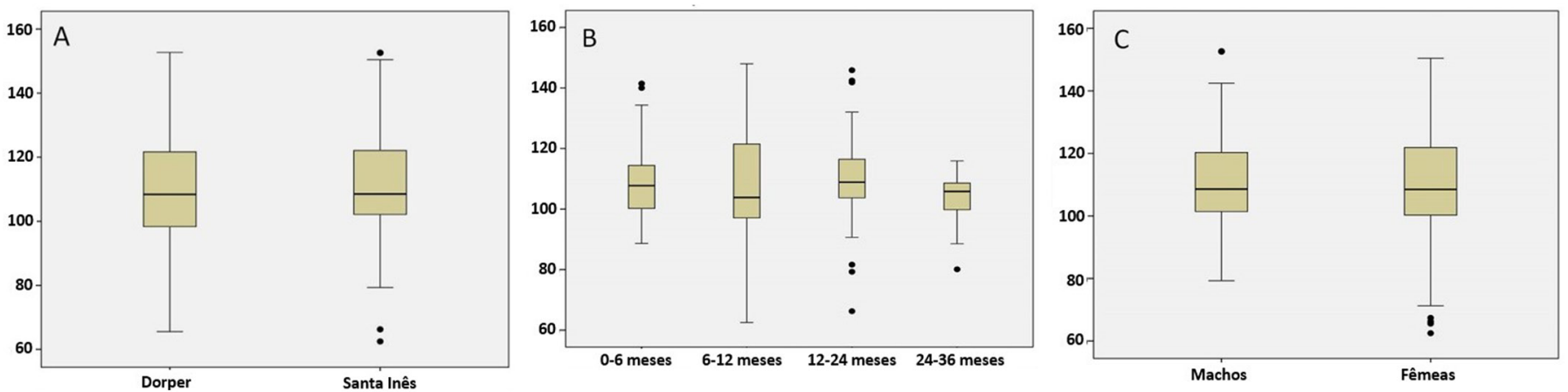

Fig.2. Distribuição dos dados de mensuração do íon cloreto sérico para as variáveis (A) raça, (B) idade e (C) sexo. 

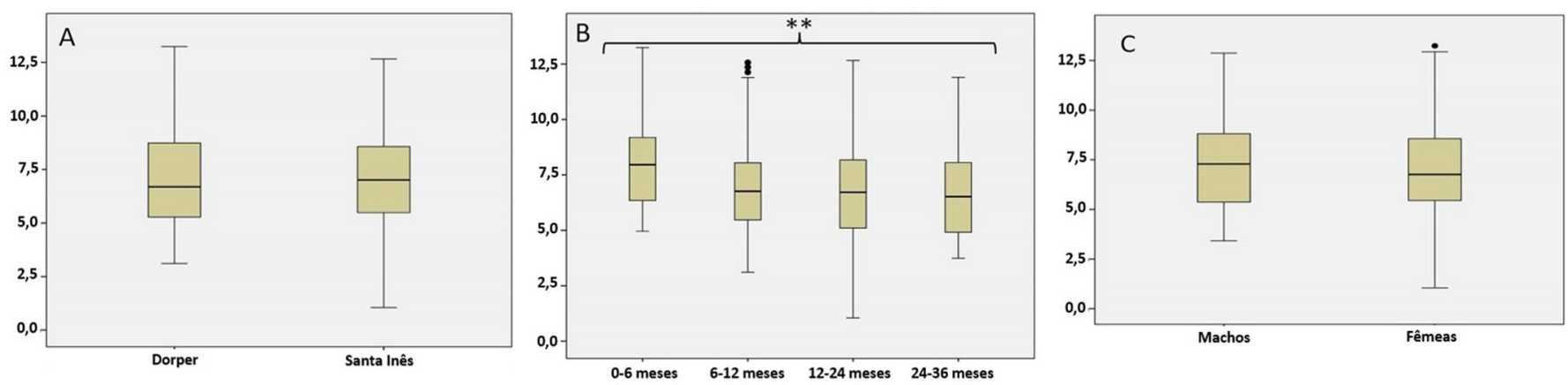

Fig.3. Distribuição dos dados de mensuração do íon fósforo sérico para as variáveis (A) raça, (B) idade e (C) sexo. 0 símbolo “**” representa diferença estatística no teste one-way ANOVA no grau de significância de $p=0,005$.
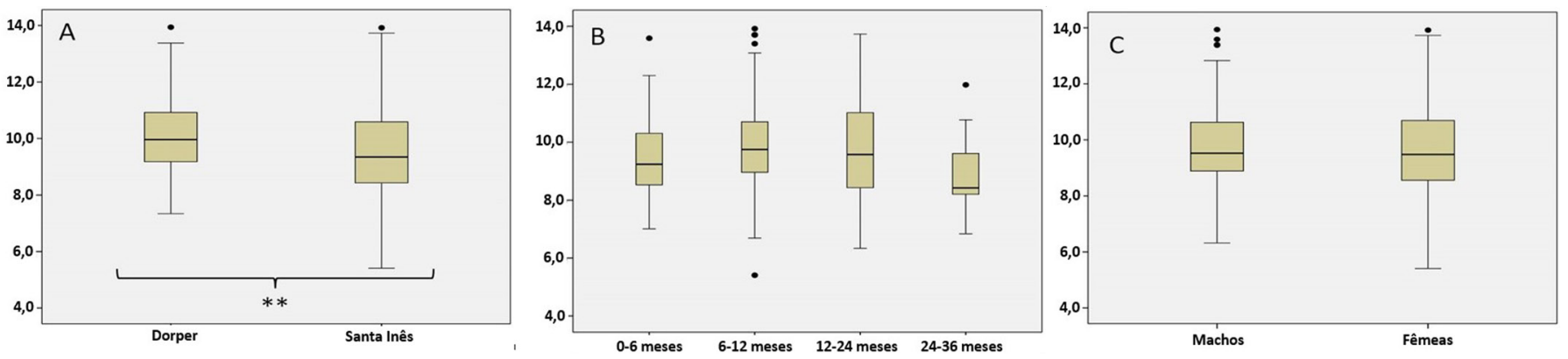

Fig.4. Distribuição dos dados de mensuração do íon cálcio sérico para as variáveis (A) raça, (B) idade e (C) sexo. 0 símbolo “**” representa diferença estatística no teste one-way ANOVA no grau de significância de $p=0,001$.

Observa-se que houve significância estatística relacionada à raça, com $p=0,001$. Com relação ao sexo e à idade, não houve significância estatística. A Figura 2 mostra os resultados para a quantificação de cloretos séricos, de acordo com a raça estudada (2A), idade (2B) e sexo (2C); não houve significância estatística para nenhum dos parâmetros avaliados. A Figura 3 mostra os resultados para a medição de fósforo sérico, de acordo com a raça estudada (3A), idade (3B) e sexo (3C), e ocorreu significância estatística relacionada à faixa etária, com $p=0,005$. A Figura 4 mostra os resultados para a mensuração de cálcio sérico, de acordo com a raça estudada (4A), idade (4B) e sexo (4C). Observa-se que houve significância estatística quanto às raças estudadas, sendo $p=0,001$.

Os intervalos de referência obtidos na análise, com relação aos ovinos em geral e com relação às raças estudadas estão apresentados no Quadro 3, onde pode-se observar que os valores dos intervalos obtidos para cada uma das raças estudadas não diferem em cada eletrólito com exceção do cálcio, onde a raça Dorper apresentou o valor do limite inferior do intervalo consideravelmente superior à raça Santa Inês. No Quadro 4, estão representados os resultados obtidos de acordo com o sexo. Observa-se que quase não há diferença entre os valores dos intervalos de machos e fêmeas para os eletrólitos magnésio e cloretos, e que para os eletrólitos fósforo e cálcio existe uma pequena diferença, não significativa. No Quadro 5, estão representados os resultados obtidos de acordo com a faixa etária, onde é visto que para os eletrólitos magnésio e cálcio não houve diferença entre os intervalos obtidos para cada faixa etária. Para os cloretos, houve uma diferença entre os limites inferiores dos intervalos obtidos, principalmente entre as faixas etárias de 0 a 6 meses e de 6 a 12 meses. Já para 0
Quadro 3. Intervalos de referência obtidos neste estudo para os analitos magnésio, cloretos, fósforo e cálcio em ovinos sem consideração de raça, e considerando as raças estudadas, e comparação com intervalos já publicados

Eletrólito/ n Intervalo de Referência em Intervalo de Referência em raça $\mathrm{mg} / \mathrm{dL}$ (este estudo) $\mathrm{mg} / \mathrm{dL}$ (Kaneko et al. 2008)

\begin{tabular}{lccc}
\hline Magnésio & & & \\
Geral & 678 & $1,83-3,07$ & $2,2-2,8$ \\
Dorper & 134 & $1,94-3,05$ & - \\
Santa Inês & 304 & $2,05-3,07$ & $128-148$ \\
$\begin{array}{l}\text { Cloretos } \\
\text { Geral }\end{array}$ & 666 & $77,39-142,37$ & - \\
Dorper & 134 & $73,57-142,37$ & - \\
Santa Inês & 294 & $84,18-145,82$ & $1,2-2$ \\
Fósforo & 678 & $3,03-12,1$ & - \\
Geral & & & - \\
Dorper & 131 & $3,49-12,84$ & \\
Santa Inês & 311 & $3,72-12,11$ & $5,1-5,5$ \\
Cálcio & & & - \\
Geral & 570 & $6,89-13,22$ & - \\
Dorper & 105 & $7,77-13,18$ & \\
Santa Inês & 264 & $6,62-13,48$ &
\end{tabular}

fósforo, a faixa etária de 0 a 6 meses apresentou um intervalo bastante superior ao das demais. Para os animais com idade superior a 24 meses não foi possível estabelecer os intervalos para nenhum dos eletrólitos estudados, devido aos poucos animais testados pertencentes a esta faixa.

\section{DISCUSSÃO}

No presente estudo, foram determinados intervalos de referência séricos para os eletrólitos magnésio, cloretos, fósforo e cálcio para as raças Dorper e Santa Inês. Assim como descrito por Lepherd et al. (2009), houve dificuldade na comparação direta da maioria dos resultados com outros já 
Quadro 4. Intervalos de referência estabelecidos neste estudo para os analitos magnésio, cloretos, fósforo e cálcio em ovinos sem divisão por sexo, e considerando a variável sexo, e comparação com intervalos já publicados \begin{tabular}{lrrr}
\hline $\begin{array}{l}\text { Eletrólito/ } \\
\text { sexo }\end{array}$ & $\mathrm{n}$ & $\begin{array}{c}\text { Intervalo de Referência em } \\
\mathrm{mg} / \mathrm{dL} \text { (este estudo) }\end{array}$ & $\begin{array}{l}\text { Intervalo de Referência em } \\
\mathrm{mg} / \mathrm{dL} \text { (Kaneko et al. 2008) }\end{array}$ \\
\hline
\end{tabular}

\begin{tabular}{lccc}
\hline Magnésio & & & \\
Geral & 678 & $1,83-3,07$ & $2,2-2,8$ \\
Macho & 136 & $1,98-3,09$ & - \\
Fêmea & 301 & $2,03-3,04$ & - \\
Cloretos & & & $128-148$ \\
Geral & 666 & $77,39-142,37$ & - \\
Macho & 136 & $81,24-148,26$ & - \\
Fêmea & 291 & $81,11-145,36$ & $1,2-2$ \\
Fósforo & & & - \\
Geral & 678 & $3,03-12,1$ & - \\
Macho & 134 & $4,06-12,7$ & \\
Fêmea & 308 & $3,53-12,11$ & $5,1-5,5$ \\
Cálcio & & & - \\
Geral & 570 & $6,89-13,22$ & - \\
Macho & 112 & $7,53-13,43$ & \\
Fêmea & 257 & $6,7-13,34$ &
\end{tabular}

Quadro 5. Intervalos de referência estabelecidos neste estudo para os analitos magnésio, cloretos, fósforo e cálcio em ovinos sem divisão de faixa etária, e considerando a variável faixa etária, e comparação com intervalos já publicados

\begin{tabular}{lccc}
\hline Eletrólito/ & $\mathrm{n}$ & $\begin{array}{c}\text { Intervalo de Referência } \\
\text { idade }\end{array}$ & Intervalo de Referência \\
& & em $\mathrm{mg} / \mathrm{dL}$ & $\mathrm{em} \mathrm{mg/dL}$
\end{tabular}

\section{Magnésio}

Geral

0 - 6 meses

$6-12$ meses

678

45

91

12 - 24 meses 73

Cloretos

Geral

0 - 6 meses

$6-12$ meses

12 - 24 meses

Fósforo

Geral

0 - 6 meses

$6-12$ meses

12 - 24 meses

Cálcio

Geral

0 - 6 meses

$6-12$ meses

12 - 24 meses (este estudo)

(Kaneko et al. 2008)

descritos em literatura, visto que a maioria dos estudos em ovinos não descreve intervalos de referência específicos para sexo, raça e faixa etária. Os resultados obtidos foram comparados com os intervalos de referência propostos na literatura e amplamente utilizados por laboratórios clínicos veterinários (Kaneko et al. 2008); apesar deste trabalho não fornecer dados para a comparação com os fatores supracitados, foi possível perceber que os intervalos de referência dos quatro eletrólitos estudados já propostos em literatura para ovinos foram muito diferentes dos valores encontrados durante o presente estudo. Uma hipótese para justificar tal resultado é a diferença de manejo e das condições edafoclimáticas, o que confirma a necessidade de intervalos de referência diferentes para animais de regiões diferentes, como foi demonstrado por Rice \& Hall (2007) no estado de Washington (Estados Unidos) e por Poppenga e colaboradores (2012), também nos Estados Unidos, no estado da Califórnia.

Borjesson et al. (2000) citam que as diferentes raças de ovinos e das demais espécies animais necessitam de intervalos de referência específicos para os valores hematológicos e bioquímicos. Para as raças Dorper e Santa Inês, analisadas neste estudo, foram encontrados valores muito semelhantes para o eletrólito magnésio, apesar de existir diferença estatística significativa $(p=0,001$, com $95 \%$ de confiança). Nenhum trabalho anterior ao presente estudo menciona resultado semelhante a este para nenhum dos eletrólitos estudados, sendo sempre sugeridas análises posteriores para a confirmação dos intervalos do íon magnésio para as raças supracitadas. Apesar de haver diferença entre os valores dos limites inferiores dos intervalos, não houve significância estatística relacionada às raças estudadas para os íons cloretos, mas deve-se citar que Rice e Hall (2007) também sugerem intervalos de referência específicos para cada raça. Com relação ao fósforo, não houve significância estatística nem diferença entre os valores dos intervalos obtidos relacionadas às raças estudadas. 0 nível de fósforo está intimamente ligado aos níveis de cálcio (Oliveira 2011), mas pelo fato de os animais analisados serem frequentadores de exposições agropecuárias, provavelmente esses animais são rigorosamente suplementados em sua alimentação, o que explica valores tão mais uniformes para este mineral. Para o cálcio, houve uma grande diferença entre os valores dos limites inferiores dos intervalos obtidos para as raças, sendo a significância estatística igual $\operatorname{com} p=0,001$, com $95 \%$ de confiança. Como a raça Dorper apresenta taxas de crescimento e desenvolvimento maiores que a raça Santa Inês (Carneiro et al. 2007), o eletrólito apresenta níveis mais elevados para a primeira raça, confirmando os resultados de Lepherd e colaboradores (2009).

Contrariando os trabalhos de Borjesson et al. (2000), Rice \& Hall (2007) e Lepherd et al. (2009), não houve significância estatística relacionada ao sexo para nenhum dos eletrólitos estudados, sugerindo um intervalo único para os dois gêneros. Contudo, os valores dos limites inferiores dos íons fósforo e cálcio apresentaram pequena diferença para os gêneros, sugerindo que estes eletrólitos podem apresentar intervalos de referência diferenciados para machos e fêmeas quando um universo maior de amostras é testado.

A faixa etária dos animais influencia na concentração sérica de um grande número de analitos (Mohri et al. 2007) e no presente estudo não foi diferente. É possível notar que os valores dos intervalos obtidos para os íons magnésio variam de forma crescente, aumentando à medida que o animal envelhece. Este fato pode ser explicado pelo tipo de alimentação dos animais, pois os animais mais jovens alimentam-se quase que exclusivamente do leite materno e os adultos alimentam-se basicamente de forragens, a principal fonte de magnésio dos animais mantidos a campo (Oliveira 2011). Apesar de não existir significância estatística, esses resultados sugerem atenção durante a interpretação de análises deste eletrólito nos animais. Para os íons clore- 
tos também não houve significância estatística relacionada à idade, mas os animais mais jovens apresentaram o valor do limite inferior do intervalo visivelmente diferente das demais faixas etárias. Já foi descrito que alta ingestão de sal por ovelhas durante a gestação pode influenciar a nefrogênese do feto (Tay et al. 2012), e especial atenção deve ser dada aos níveis de cloretos por essa espécie animal. Os níveis de cloro também estão diretamente ligados à ingestão de sal mineral, e, como o consumo de sal pelos animais desta faixa etária é menor que nas demais (Oliveira 2011), esse resultado sugere que animais mais jovens devem possuir intervalo de referência diferenciado para os íons cloretos.

Com relação ao fósforo, a diferença entre os valores do intervalo obtido para os animais com idade entre zero e seis meses foi muito significativa $(p=0,005$, com $95 \%$ de confiança). 0 fósforo está envolvido na maior parte das reações metabólicas do organismo (metabolismo de lipídios, carboidratos e proteínas) e nas reações de formação de energia (ATP), além de ser um dos principais minerais da composição óssea (Oliveira 2011), e já foi descrita a importância do consumo de oxigênio e produção de ATP na performance de animais de produção (Salin et al. 2015). Como os animais jovens possuem o metabolismo mais eficiente (rápida digestão e absorção de nutrientes) e estão na fase de crescimento (desenvolvimento ósseo), os altos níveis de fosfato nesta faixa etária são justificáveis.

Para o eletrólito cálcio não houve significância estatística relacionada à idade, sendo os valores dos intervalos de referência das quatro faixas etárias bastante próximos. Como 98 a 99\% do cálcio presente no organismo encontra-se nos ossos e dentes dos animais de todas as idades (Dantas et al. 1999), os níveis séricos do íon não diferem muito entre as faixas etárias. Não foi possível aferir o intervalo deste eletrólito para os animais pertencentes à faixa etária de 6-12 meses devido ao baixo número de amostras validadas durante o experimento.

As concentrações sanguíneas de cálcio e de fósforo são importantes para os animais jovens por eles apresentarem uma maior eficiência na absorção desses minerais em decorrência da alta taxa de desenvolvimento ósseo, justificado pela maior reabsorção renal e maior mobilização óssea do fósforo em animais em crescimento. A deficiência de fósforo é mais comum em animais sob pastejo, pois a maior parte das gramíneas estabelecidas em solos de regiões tropicais é deficiente nesse mineral. Deve-se observar que o controle do metabolismo do fósforo está associado ao do cálcio e que uma forte relação deve ser mantida paro o controle da homeostase destes dois elementos (Bezerra 2006).

Concluindo-se, os intervalos de referência dos eletrólitos magnésio e cálcio devem ser diferenciados para as raças Dorper e Santa Inês, devido aos diferentes resultados obtidos entre as mesmas. Com relação ao sexo, mesmo não havendo significância estatística, os resultados apresentados sugerem que deve haver separação entre os intervalos de machos e fêmeas. Para as faixas etárias, os resultados indicam que se deve estabelecer um intervalo de referência especial para os animais com idade entre zero e seis meses, mas um número maior de amostras pode levar ao aparecimento de diferenças robustas.

\section{CONCLUSÕES}

Os resultados obtidos neste estudo permitem concluir que existe a necessidade de se desenvolver intervalos de referência para eletrólitos séricos específicos para ovinos criados em condições zootécnicas e climáticas brasileiras, visto que foi possível observar diferenças estatísticas significativas dos intervalos de referência aqui obtidos daqueles que são descritos na literatura científica e que foram desenvolvidos em outros países.

Também deve-se frisar que os resultados apontam para o fato da necessidade de obtenção de valores de referência específicos para diferentes raças e faixas etárias em ovinos.

Agradecimentos.- Os autores gostariam de agradecer à Sra. Francisca Soares (LABIMUNO, ICS-UFBA) pela assistência técnica na realização dos experimentos, e à Fundação de Apoio à Pesquisa e Extensão (FAPEX, BA) pelo auxílio financeiro ao projeto. Bianca Cardeal Souza foi bolsista de mestrado da CAPES.

\section{REFERÊNCIAS}

BaginskE.S.1969. Determination of phosphate and phosphomonoesterases in biologic materials. Am. J. Med. Technol. 35:475.

Benavides M.V., Sonstegard T.S., Kemp S., Mugambi J.M., Gibson J.P., Baker R.L., Hanotte O., Marshall K. \& Van Tassell C. 2015. Identification of novel loci associated with gastrointestinal parasite resistance in a Red Maasai x Dorper backcross population.PLoS One 10:e0122797.

Bezerra L.R. 2006. Desempenho e comportamento metabólico de cordeiros da raça Santa Inês alimentados com diferentes concentrações de Spirulina platensis diluída em leite de vaca. Dissertação de Mestrado em Zootecnia, Universidade Federal de Campina Grande, Patos, PB. 41p.

Bohuon C. 1962. Microdetermination of magnesium in various biological media. Clin. Chim. Act. 7:811.

Borjesson D.L., Christopher M.M. \& Boyce W.M. 2000. Biochemical and hematologic reference intervals for free-ranging desert bighorn sheep. J. Wild. Dis. 36:294-300.

Bucci M., Vinagre E.C., Campos G.E.R., Curi R. \& Pithon-Curi T.C. 2006. Efeitos do treinamento concomitante, hipertrofia e endurance do músculo esquelético. Revta Bras. Ciênc. Movim. 13:17-28.

Burtis C.A. \& Ashwood E.R. 1994. Tietz Textbook of Clinical Chemistry. Saunders Company, Philadelphia, p.1366-1367.

Carneiro P.L.S., Malhado C.H.M., Souza Júnior A.A.O., Silva A.G.S., Santos F.N., Santos P.F. \& Paiva S.R. 2007. Desenvolvimento ponderal e diversidade fenotípica entre cruzamentos de ovinos Dorper com raças locais. Pesq. Agropec. Bras. 42:991-998.

CLSI 2008. Defining, Establishing, and Verifying Reference Intervals in the Clinical Laboratory: approved guideline. Clinical and Laboratory Standards Institute, Wayne. 59p.

Cooper G.R. 1983. Selected Methods of Clinical Chemistry. AACC, Washington, p.125.

Cruz C.A.C. 2009. Caracterização lipídica da paleta de cordeiros Santa Inês. Dissertação de Mestrado em Engenharia de Alimentos, Universidade Estadual do Sudoeste da Bahia, Itapetinga, BA. 82p.

Dantas M.O., Sousa E.B.C., Oliveira Filho J.J., Rodrigues M.E. \& Souza B.B. 1999. Avaliação dos níveis plasmáticos de cálcio e fósforo de bovinos leiteiros suplementados com ortofosfato bicálcico e cloreto de sódio. Agropec. Técnol. 20:1-7.

Friedberg R.C., Souers R., Wagar E.A., Stankovic A.K. \& Valenstein P.N. 2007. The origin of reference intervals: a college of American pathologists Qprobes study of "normal ranges" used in 163 clinical laboratories. Arch. Pathol. Lab. Med. 131:348-357.

Geffré A., Friedrichs K., Harr K., Concordet D., Trumel C. \& Braun J. 2009. Reference values: a review. Vet. Clin. Pathol. 38:288-298.

Geraseev L.C., Pérez J.R.O., Santos C.L., Prado O.V. \& Resende K.T. 2001. Composição corporal e exigências nutricionais em magnésio, potássio e sódio de cordeiros Santa Inês. Pesq. Agropec. Bras. 36:681-688 
Kaneko J.J., Harvey J.W. \& Bruss M.L. 2008. Clinical Biochemistry of Domestic Animals. Elsevier Academic Press, Amsterdam, p.194-902.

Lepherd M.L., Canfield P.J., Hunt G.B. \& Bosward K.L. 2009. Hematological, biochemical and selected acute phase protein reference intervals for weaned female Merino lambs. Aust. Vet. J. 87:05-11.

Miglio A., Antognoni M.T., Maresca C., Moncada C., Riondato F., Scoccia E. \& Mangili V. 2015. Serum protein concentration and protein fractions in clinically healthy Lacaune and Sarda sheep using agarose gel electrophoresis. Vet. Clin. Pathol. Doi: 10.1111/vcp.12302.

Mohri M., Sharifi K. \& Eidi S. 2007. Hematology and serum biochemistry of Holstein dairy calves: age related changes and comparison with blood composition in adults. Res. Vet. Sci. 83:30-39.

Oliveira D.E. 2011. Minerais: funções, deficiências, toxidez e outros aspectos da suplementação. In: Agroceres: Nutrição Animal. Disponível em <http://d.yimg.com/kq/groups/23513213/1369054970/ name/Minerais.pdf> Acesso em 30 de abril de 2015.

Peixoto L.A.O. \& Osório M.T.M. 2007. Perfil metabólico proteico e energético na avaliação do desempenho reprodutivo em ruminantes. Revta Bras. Agrociênc. 13:299-304.
Poppenga R.H., Ramsey J., Gonzales B.J. \& Johnson C.K. 2012. Reference intervals for mineral concentrations in whole blood and serum of bighorn sheep (Ovis canadensis) in California. J. Vet. Diagn. Invest. 24:531-538.

Rice C.G. \& Hall B. 2007. Hematologic and Biochemical Reference Intervals for Mountain Goats (Oreamnos americanus): effects of capture conditions. Northw. Sci. 81:206-214.

Rossi L. \& Tirapegui J. 1999. Aspectos atuais sobre exercício físico, fadiga e nutrição. Recta Paul. Educ. Fís. 13:67-82.

Salin K., Auer S.K., Rey B., Selman C. \& Metcalfe NB. 2015. Variation in the link between oxygen consumption and ATP production, and its relevance for animal performance. Proc. Biol. Sci. 282:20151028.

Tay S., Blache D., Gregg K. \& Revell D. 2012. Consumption of a high-salt diet by ewes during pregnancy alters nephrogenesis in 5-month-old offspring. Animal 6:803-810.

Wilmsen M.O., Silva B.F., Bassetto C.C. \& Amarante A.F. 2014. Gastrointestinal nematode infections in sheep raised in Botucatu, state of São Paulo, Brazil. Rev. Bras. Parasitol. Vet. 23:348-354. 